\title{
Primazia do real na construção do conhecimento científico e primazia da teorização na construção de pesquisas científicas: contribuições metodológicas a partir de Miriam Limoeiro Cardoso
}

Rosa Maria Corrêa das Neves*

Siomara Moreira Vieira Borba

\section{Resumo}

Neste artigo, reivindica-se a possibilidade de desenvolvimento de pesquisas educacionais tendo por referência a contribuição metodológica de Miriam Limoeiro Cardoso, posição que envolve dois movimentos desta pesquisa. Inicialmente, são expostas as teses da distinção entre realidade e objeto científico e da teorização como processo inicial da construção do objeto de investigação, que sintetizam o exame que autora empreende a partir dos apontamentos metodológicos de Karl Marx em seu processo de elaboração de uma teoria geral do capitalismo. A possibilidade da fecundidade de suas contribuiçóes resulta da constatação de problemas na relação entre teoria e empiria que é identificada através da sumarização de análises da pesquisa educacional brasileira até início deste século, possivelmente ainda atual.

Palavras-chave: Conhecimento Científico. Miriam Limoeiro Cardoso. Pesquisa da Educação.

\footnotetext{
* Doutora em Educação pela Universidade do Estado do Rio de Janeiro (UERJ). Pesquisadora em Saúde Pública na Fundaçáo Oswaldo Cruz.

** Doutora em Educação pela Pontifícia Universidade Católica do Rio de Janeiro (PUC/Rio). Professora Associada da Faculdade de Educaçáo, da Universidade do Estado do Rio de Janeiro (UERJ).
} 


\section{Introdução}

O debate teórico-metodológico de pesquisas na área de educação no Brasil não é novo e, de diferentes ângulos, vem sendo posto na medida em que se realizaram e continuam a se realizar as próprias pesquisas. Passados quase cinquenta anos desde que a pesquisa em educação brasileira se desloca institucionalmente, concentrando-se majoritariamente na pós-graduação stricto sensu, as pesquisas daí derivadas têm sido continuamente analisadas por pesquisadores que discutem menos seus resultados e mais o seu processo de construção, o método. Ao longo dessa trajetória da pós-graduação stricto sensu em educação, uma larga trajetória de pesquisa educacional se afirma como atividade consolidada, resultando numa produçáo de conhecimentos que não estão isentos de serem problematizados em sua dimensão processual, metodológica, o que tem sido nosso objeto de estudos e pesquisas.

Nessa direção metodológica, expomos dois movimentos de pesquisa: em primeiro plano, a exposiçáo de teses fundamentais do conhecimento científico distinçáo entre realidade e objeto científico e teorizaçáo como processo inicial da construção do objeto de investigação -, teses hauridas de posições metodológicas de Miriam Limoeiro Cardoso, socióloga brasileira com relevante contribuição sobre desenvolvimentismo como ideologia dominante. Num segundo plano, expomos a sumarização de análises da pesquisa educacional brasileira até início deste século, através da qual identificamos constantes problemas metodológicos na relação entre teoria e realidade, dificuldade possivelmente ainda atual.

Entendemos as contribuiçôes de Miriam Limoeiro Cardoso sobre a construção teórica do objeto científico, como perspectiva teórica que possibilita o enfrentamento dos limites metodológicos que identificamos na pesquisa educacional.

\section{Realidade, teorização, experimentação e objetivação: contribuições metodológicas da produção científica na perspectiva de Miriam Limoeiro Cardoso}

Miriam Limoeiro Cardoso, cientista social brasileira, apresenta uma original tese do pensamento social brasileiro para crítica de formulaçóes da política nacional desde 1950 até meados dos anos de 1960. Em 1972, em plena vigência do "milagre econômico", assim chamado o surto de 
crescimento de 1968 a 1973 da ditadura repressiva brasileira, instaurada pelo golpe militar de 1964, Cardoso defende sua tese sobre desenvolvimentismo como ideologia dominante. Para nossa proposição da reflexão a respeito do conhecimento científico, o rigor com que toma o seu doutoramento, rigor que envolve um esforço de pesquisa em distintas dimensóes da produção científica - epistemológica, metodológica, teórica e de campo, através da análise de documentos e entrevistas com ex-presidentes brasileiros -, credenciam-na como referência de nossas pesquisas, que refletem nosso interesse de estudos sobre método como problema teórico. É também oportunidade de divulgação de suas publicaçôes, ainda pouco reconhecidas mais amplamente, parte das quais temos reunido e aqui expomos apenas aquelas que travam um debate metodológico como objeto central. Entre essas, elencamos de início, nos anos de 1970, as teses subsidiárias de seu doutoramento "Nota metodológica: sobre a construção de categorias" e "Indicações para uma análise teórica da ideologia", reunidas em publicação de 1977 pela mexicana Editora Era, sob o título La construcción de conocimientos: cuestiones de teoría y método. Em 1971, escreve "O mito do método" (CARDOSO, 1976), publicação do Boletim Carioca e Geografia que nos dias atuais é acessível na rede mundial de computadores ${ }^{1}$.

Seu projeto de tese foi aceito por Florestan Fernandes (1920-1995), entấo professor da Universidade de São Paulo (USP). Em 1972, defende sua tese de doutorado, sob o título "Ideologia do desenvolvimento: Brasil, JK, JQ", publicada pela primeira vez no México pela Editora Siglo XXI em 1975 sob o título La ideología dominante, e, no Brasil, publicada em livro pela Editora Paz e Terra, em 1978, com o mesmo título da tese.

Além dos escritos de inícios da década de 1970, Cardoso dá continuidade a seus estudos e desenvolve uma intensa produção dedicada a questôes de teoria e método. Desse conjunto de publicações, há suas anotações de estudo da "Introdução à crítica da economia política"2, escritas por Marx em 1857, que mereceu da autora algumas publicações: a primeira, com o título A periodização e a ciência da história: observaçóes preliminares, de junho de 1977; a segunda, em 1979, Para o conhecimento dos objetos históricos: questóes metodológicas; e outra ainda, em 1990, Para uma leitura do método em Karl Marx; anotaçôes sobre a 'Introdução' de 1857.

De sua extensa e densa produçãa ${ }^{3}$, nossa argumentação recolhe suas teses sobre realidade e conhecimento científico que julgamos necessárias como objeto de reflexão na área de educação. A partir do conjunto de contribuições que têm 
o conhecimento científico como objeto de sua análise, enfatizamos a distinção que a autora faz entre objeto real e objeto científico, distinção que envolve um conjunto de outras teses que aqui apresentaremos brevemente em seus nexos com a relação entre realidade e teoria, questão essencial para a produção de conhecimento científico.

Nossa apresentação sublinha as posiçóes sobre conhecimento científico e realidade e suas consequências metodológicas na produção do conhecimento científico. Essas consequências permitem demonstrar que são indissociáveis as dimensões epistemológicas e metodológicas na produção do conhecimento científico, ou seja, uma determinada concepção de realidade e de relaçôes entre conhecimento e realidade impóe um método específico e, por conseguinte, um método específico supóe uma determinada concepção de realidade e de relaçôes entre conhecimento e realidade. Para além da exposição de parte de suas teses epistemológicas, cabe dizer que elas são subsidiárias da produção científica que objetiva realizar no curso do doutoramento, não sendo assim uma divagação diletante, mas parte da produção de uma tese científica, sociológica. Suas referências de pesquisa epistemológica, pesquisa sobre a natureza do conhecimento científico e as implicações metodológicas desse conhecimento, são especialmente Gaston Bachelard, Jean Piaget e Karl Marx, sendo este último de quem extrai a teorização como objeto de análise metodológica ou como "caso" exemplar de uma rigorosa relaçáo entre processo de construção de uma teoria científica e de crítica e autocrítica do estatuto do conhecimento histórico.

\section{Objeto real e objeto teórico: distinções e relações na produção do conhecimento científico}

No desenvolvimento das ciências, tem vigorado a tese de que seu objeto é a realidade, independentemente do estatuto do real, natural ou histórico. Esta afirmação - de que o objeto da investigação científica é a realidade - pode parecer uma afirmaçáo óbvia, simples, sem problemas; no entanto, não tem sido desde as origens das ciências na modernidade. Assim, considerando a realidade como objeto de conhecimento, algumas questóes frequentemente se levantam: Que real é esse sobre o qual o trabalho de investigação se volta? Qual é o estatuto do real frente ao desenvolvimento do trabalho de investigaçáo? Como conhecer a realidade? Como o cientista deve iniciar seu trabalho investigativo sobre a 
realidade: partir da realidade como vivida, experimentada e dada, desprovida de teorias ou considerar teorias? Que articulação há entre teoria e realidade?

As questôes parecem infindas e, na tradição teórica que problematiza a cientificidade, simultânea a seu desenvolvimento desde seus começos, podem ser tratadas através de tomada de posições diferenciadas e divergentes. Não temos a pretensão de exaustivamente expô-las nem sequer tratá-las. Circunscrevemos nossa contribuição à exposição das principais teses de Miriam Limoeiro Cardoso sobre a relação entre realidade e conhecimento científico, além de sua (e nossa) reivindicação da distinção entre objeto real e objeto teórico e da consequência lógica de que o processo de investigação científica inicie pela consideração teórica e não pela consideração primaz de experiências.

Em primeiro, é necessário afirmar a tese realista da epistemologia de Limoeiro Cardoso - de afirmação da realidade -, própria das ciências em geral e, em especial, da tradição marxista na produção do conhecimento sobre a realidade histórica. A tese realista está afirmada em seus escritos metodológicos de modo categórico: "no fundo é a realidade que importa" (CARDOSO, 1976 p. 64-65) e está reiterada em diferentes publicaçóes suas, sendo possível reconhecer as contribuiçóes da autora sobre o estatuto de realidade e também implicaçóes desse estatuto frente ao processo de produção do conhecimento científico.

Uma vez afirmada, a tese da existência da realidade não é desenvolvida senão em seu estatuto, ou seja, na elucidaçáo do que seja realidade ou o real. Entre suas teses iniciais temos a posição de que a realidade nos afeta - "fornece elementos que os sentidos podem captar" (CARDOSO, 1976, p. 65) e que essa afeição, contribuição já secular da Psicologia, é seletiva tanto pelo aparato orgânico quanto pelas relaçóes sociais. Cabem suas proposiçóes resultantes de estudos de teorias da percepção de Jean Piaget (1970, p. 108 apud CARDOSO, 1976, p. 88): "a própria percepção não consiste em uma simples leitura dos dados sensoriais, mas comporta uma organização ativa, na qual intervêm decisóes e pré-inferências e que é devida à influência sobre a percepção como tal do esquematismo das ações ou das operaçôes". E de Krech e Crutchffild (1948, p. 92 apud CARDOSO, 1976, p .88): "o que é selecionado pela percepção não é somente função do nosso aparato preceptor definido fisiologicamente, mas é também parcialmente função do nosso colorido e modelado pela nossa cultura".

A realidade, além de fato existir e afetar indivíduos e grupos, é complexa. Diz Cardoso (1979, p. 48): 
$\mathrm{Na}$ sociedade, como na natureza, não há fenômenos simples. Mesmo as sociedades ditas primitivas sáo complexas. Mesmo as partes menores da matéria contêm grande complexidade. O que existe concretamente são complexidades maiores e menores, algumas das quais podem ligar-se organicamente, quer em termos estruturais, quer em termos históricos, sem que seja necessário conceber suas relaçôes como de continuidade.

Resultado da complexidade da realidade, o real tem caráter determinado, pois a realidade não significa um fato nem um amontoado de fatos, nem experiências ou um conjunto de experiências, mas, sim, um conjunto de fatos associados entre si, por relaçôes de diferentes ordens "entre os fatos", relaçóes que não são imediatamente perceptíveis, que não nos afetam diretamente. Esta proposição remete ao caráter determinado da realidade natural e também da realidade social, afirmação que Cardoso (1990) desenvolve através do exame das notas metodológicas de Karl Marx.

Cardoso (1990) reporta a Marx nas críticas teóricas que empreendeu na análise do capitalismo, demonstrando que o início de sua produção científica sobre capitalismo se dá pela teorização das teses econômicas mais gerais de sua época. Marx (1974) considerando o caráter concreto, complexo da realidade e sua determinação histórica e dialética, compreende os limites dessas teorias gerais na apreensão da realidade em exame, no caso, a essência do modo de produção capitalista, suas origens e desenvolvimento e tendências históricas. Dessa forma, Cardoso (1990, p. 20) sintetiza, assim, algumas das notas teóricas de Marx:

No caso da economia, como aquilo de que ela trata é a produção, pareceria correto começar a pensá-la economia, produção - por quem a faz, que é também em quem ela se apoia: a população. Supóe-se, pois, que a população é o concreto, ou é o que mais concretamente representa o concreto. O que Marx pergunta é se esse "concreto", assim exposto, faz sentido. E a resposta é não. Porque tal "concreto" só ganha seu sentido quando a análise vai descobrindo determinaçóes. Isto porque a realidade social é uma realidade determinada: os fatos sociais são como são por alguma razão. Há relaçôes específicas que os engendram, eles respondem a uma 
certa causalidade. Neste sentido, são determinados e, assim, sua explicação só pode ser conseguida quando se apreende sua determinação.

Diante do estatuto da realidade, afirmada como complexidade, e de seu caráter determinado, já se coloca o conhecimento como problema: é no âmbito dessa relaçáo entre realidade complexa e determinada que seu conhecimento coloca uma relação processual e, portanto, não imediata. Este caráter processual da produção do conhecimento científico exige uma compreensão profunda da relação entre conhecimento e realidade e, como consequência, um processo de produção que reflita a profundidade dessa compreensão.

Para Cardoso (1976, p. 63), o conhecimento científico é um processo resultante do sujeito que busca o conhecimento da realidade, ação que coloca em relação dois elementos - "o sujeito e o objeto: o conhecimento é o resultado da relação entre um sujeito que se empenha em conhecer e o objeto de sua preocupação". Em uma de suas afirmaçóes sobre essa relaçáo - "a realidade ela mesma só se torna objeto como termo da relação, como coisa pensada" (CARDOSO, 1976, p. 65, grifos da autora) -, afirma-se como tese epistemológica que a realidade, coisa pensada, é o objeto da relação, aquilo que o sujeito busca conhecer. Usando os termos da autora, esta tese impóe que, ao fim do processo de conhecimento, o sujeito pode chegar a mudar seus pensamentos sobre a "coisa pensada", o que não significa mudar "a coisa", a realidade propriamente dita.

A consequência metodológica dessa posição - modificar o conhecimento que se tem sobre a realidade não significa necessariamente modificar a realidade - é de fundamental importância para a crítica de uma concepção empirista, supostamente científica, e sua suposição de que é científica a sistematização rigorosa de experiências, equívoco que resulta da identidade entre percepção da realidade e realidade.

Tal identidade, que restringe realidade à percepção, desconsidera que percepção é apreensão de particularidade(s) de uma totalidade, complexamente articulada de particularidades determinadas. Nessa perspectiva, reivindica-se a realidade como parte do processo de produção do conhecimento científico, e o início da pesquisa se dá pelas coisas tais quais "são" - suas características e relaçóes perceptíveis -, julgando que se inicia a pesquisa científica pelas coisas em si próprias e não pelas percepçóes sobre as coisas, percepçóes em que são decisivas 
todas as relaçóes sociais do sujeito que pensa a coisa. Desde uma perspectiva empirista, o rigor teórico parte da percepção emanada das experiências subjetivas sem que esteja presente o cuidado de problematizar o caráter particular das próprias experiências. Conduzidas segundo essa concepção, o resultado de pesquisas tende a ser generalização de descrições do suposto real, descrições que são ponto de partida e conclusão do processo de produção teórica, descriçôes sempre subjetivas, pois sempre referenciadas na(s) particularidade(s) do sujeito que as produz. De forma nenhuma esse é o ponto de partida do conhecimento para Miriam Limoeiro Cardoso (1978, p. 25), que afirma categoricamente que "as evidências são sistematicamente enganadoras".

Cabe acrescentar que a negação da percepção como fonte do conhecimento não é a negação da possibilidade de produção do conhecimento objetivo da realidade, mas a negaçáo da possibilidade de que o conhecimento objetivo da realidade, próprio da epistemologia científica, resulte da sistematizaçáo das percepçóes, das experiências ou da prática, expressáo correntemente usada na área de educação. A negação da posição firmada nas percepçóes e evidências necessariamente implica no reconhecimento do caráter subjetivo da sua suposição, decorrência da reivindicação da particularidade seja do objeto, seja do sujeito, um absurdo sociológico comentado por Limoeiro Cardoso (1976, p. 63, grifo nosso):

Pode-se supor, seguindo uma epistemologia espontânea, que esta relação se dê entre o investigador, considerado empiricamente, como indivíduo concreto, personalizado, e o pedaço da realidade, também concreto, que ele tenha decidido pesquisar. Cada pessoa seria inteiramente responsável pelas formulaçóes que fizesse, pelas explicaçôes que desse, porque seu pensamento teria sido elaborado a partir do contato com o objeto, que sendo concreto $e$ independente dele, não teria como negá-lo. Para sair-se bem bastaria que ele não se deixasse enganar por si mesmo, isto $e$ é, se neutralizasse para impedir interferências deformadoras do objeto, que deveria ser colbido em toda a sua pureza.

Entretanto parece que existem limitaçôes sérias à consideraçáo deste duplo empirismo na formação do conhecimento, quer quanto ao sujeito, quer quanto ao objeto, e consequentemente quanto a sua orientaçáo pelo real. Relativamente ao sujeito, devemos anotar primeiro 
que o pensamento não existe independente de alguém que pense, ao mesmo tempo em que só existe como coisa pensada. O sujeito que pensa aprende a pensar dentro da sociedade em que se encontra, antes de se descobrir como ser pensante. Aprende a pensar se comunicando com os que o cercam, e com a linguagem incorpora a forma de pensar que ela contém, como própria. Ainda quando se considera apenas essa comunicação nos seus aspectos mais simples e imediatos, já se pode verificar que nela se acham com destaque as explicaçóes que a sociedade em questão dá de si mesma e do seu mundo.

Cabe notar que o relacionamento pensamento/objeto não é feito fundamentalmente a partir de cada ser pensante individual e específico, mas está baseado na explicação parcial concretamente aceita pela sociedade ou pelo grupo social, conforme ela é assimilada pelo sujeito, tendo importância a sua posição dentro dela ou dele.

A distinção entre conhecimento e realidade que, no plano metodológico do trabalho científico, resulta na distinção entre objeto teórico e objeto real previne esse duplo empirismo na produção científica e por nós é considerada também uma síntese em coerência com o longo debate que acompanhou as ciências, em suas origens na modernidade, revelando-se um conhecimento que deva ser orientado metodologicamente contra a pura sistematização de experiências e contra pura sistematização de ideias, valorizando tanto ideias lógicas quanto a própria realidade, que, como afirma Cardoso (1976), tem a palavra final.

Primazia da realidade, negação da experiência, negação do subjetivismo e reivindicação da objetividade na produção de conhecimentos científicos envolvem orientações metodológicas que são expostas por Cardoso (1976) teorização, experimentação e objetivação -, como as consequências necessárias da tese realista, dentre as quais expomos de modo mais detalhado a teorização, sendo a afirmação completa das próprias teses realistas da autora nosso ponto de partida:

No fundo, é a realidade que importa, mas não é ela que comanda o processo da sua própria inteligibilidade. Já a sua existência independente não é senão uma questão. 
Ela é capaz de nos sensibilizar, ela fornece elementos que os sentidos podem captar. Eles serão percebidos, apreendidos, colocados, como evidência a confirmar ou afirmar formulaçóes anteriores. (CARDOSO, 1976, p. 64-65).

O que pode parecer uma contradição na medida em que a realidade se coloca como primazia - a realidade é o que importa - e posterioridade - a realidade confirma ou infirma formulaçóes anteriores - é um duplo sinal de exigências metodológicas complementares: a realidade define a validade do conhecimento teórico-científico e o conhecimento deve ser enfrentado como "coisa pensada", através de teorias e das lógicas a que se subordinam.

Restringimos de sua contribuição a ênfase da distinção entre objeto real e objeto teórico, uma vez que tem sido nossa preocupaçáo a questão dos processos iniciais de construçáo do conhecimento científico, seja no que tange à formação do pesquisador em educação, em nosso caso, na formação propiciada pela pós-graduação stricto sensu, seja no que tange à prática da pesquisa acadêmica na área de educação que, como expusemos, tem encontrado de modo recorrente limites metodológicos, de fundo epistemológico, limites que, em nosso entendimento, relacionam-se a uma perspectiva náo propriamente científica de conhecimento.

A contribuição epistemológica de Cardoso (1976, p. 63) nega pressupostos de fundo criticados em análises sobre a pesquisa educacional brasileira: o conhecimento como resultado de generalizaçóes que partem do real tal como nos suscitam as experiências educativas. Essa perspectiva metodológica que se firma através de um sujeito que busca conhecer e de uma realidade que se dá a conhecer, que é sempre "um pedaço de realidade", como foi ressaltado por várias vezes em nossa exposição, é criticada pela autora com base nos argumentos que afirmam ser o conhecimento científico da realidade natural ou histórica, resultado de pesquisas que iniciaram pela teorização sobre o que se supóe conhecidót.

Nossos estudos têm nos possibilitado pensar o processo de construçáo do conhecimento de uma perspectiva propriamente científica, segundo a qual o objeto que se torna objeto de conhecimento náo é o real em si mesmo, não é o real na sua experiência nem em sua apreensão imediata, mas na sua condiçáo de real já pensado, já conhecido. Para que o real se torne 
objeto de conhecimento é preciso que seja um objeto teórico e construído teoricamente.

Essa forma de entendimento do conhecimento científico e seu processo cíclico indica, concretamente, uma nova forma de conceber a relação sujeito - objeto que marca o processo de conhecimento. Essa forma coloca nas duas pontas do processo investigativo a realidade náo em si mesma, mas como objeto teórico, entendendo que o processo de conhecimento científico começa e termina no campo do teórico, que não é, somente, o final do processo de conhecimento; é, ao mesmo tempo, seu começo e seu fim. O processo de conhecimento científico parte do objeto teórico, e não da apreensão imediata da experiência e da realidade suposta através das percepçóes particulares do sujeito que a investiga. Por outro lado, não termina no objeto teórico de que partiu, termina em outro objeto, também teórico, outro conhecimento científico ${ }^{5}$. A consequência dessas assertivas é que o processo de produção do conhecimento científicto, a investigação científica, não tem início na sistematização da experiência, mas na teorização, na crítica dos objetos teóricos, das teorias disponíveis através das quais é possível compreender experiências e particularidades a partir de perspectivas mais complexas. Em síntese, essa perspectiva indica uma lógica, um método para o trabalho investigativo, que, a despeito de considerar a realidade como imperativa no conhecimento científico, não atribui à realidade percebida a possibilidade e capacidade de trazer a inteligibilidade sobre si; essa lógica é construída racional, experimental e coletivamente ${ }^{6}$.

Miriam Limoeiro Cardoso (1977) empreendeu este movimento metodológico na construção de sua tese científica, resultado do esforço de sua teorizaçáo em torno do objeto de estudo - ideologia - e da experimentaçáo de suas conclusões teóricas sobre ideologia num campo empírico determinado documentos e entrevistas com ex-presidentes brasileiros -, a partir da teorização sobre desenvolvimento socioeconômico. Aliam-se de forma articulada na sua produção científica investimento em teoria do conhecimento científico, na construção teórica do objeto científico, na construção teórico-metodológica de sua hipótese, na exploração e análise do campo empírico, informadas pela teorização, processo que resulta numa tese original - o desenvolvimentismo é ideologia dominante.

\section{Revisão de análises de pesquisadores da área de educação:}




\section{limites da relação entre teoria e experiência na pesquisa educacional em nível de pós-graduação stricto sensu}

Para além da dimensão teórica sobre método e conhecimento científico, temos buscado dimensionar nossa problemática - a relação entre conhecimento científico e pesquisa educacional -, articulando investigaçóes de campo. Neste artigo, expomos alguns resultados parciais dessa direção de pesquisa: nossa revisão de análises de pesquisadores da área sobre a produção acadêmica em nível de pós-graduaçáo stricto sensu, publicadas na revista Cadernos de Pesquisa, da Fundaçáo Carlos Chagas, entre as décadas de 1970 e 2000. Em termos metodológicos, nossa opção por este periódico específico justifica-se pela sua primazia na dinâmica da pesquisa educacional brasileira em nível de pósgraduação, pois se apresenta de modo expresso como veículo de divulgação de pesquisas educacionais e inicia o ciclo de divulgação periódica de resultados de pesquisas na área, no Brasil, em 1971, sendo essa a razão de seu escopo editorial entre 1970 e 2000. Nossa revisão bibliográfica até o momento considera desde a origem do periódico, em 1971, até o número 113, publicado em 2001, último exemplar do periódico que teve pesquisa em educação como sessão temática ${ }^{7}$. Nossa exposição segue a cronologia das análises publicadas no periódico, dividida entre período anterior e posterior à produção de dissertaçôes, seguida de nossa perspectiva sobre os limites identificados através desta pesquisa, perspectiva que se articula à relação entre conhecimento científico e pesquisa educacional, especificamente às teses de Miriam Limoeiro Cardoso.

\section{Primeiras impressões sobre a pesquisa educacional brasileira: contribuições de Aparecida Joly Gouveia no período anterior à produção de dissertações e teses em educação}

Já em seus momentos iniciais, as pesquisas educacionais desenvolvidas no âmbito da pós-graduação stricto sensu passaram a ser objeto de análise e publicaçóes, sendo os primeiros estudos com esses objetivos de autoria de Aparecida Joly Gouveia ${ }^{8}(1971,1974,1976)$. A importância da autora para o debate da pesquisa educacional evidencia-se por ter inaugurado a publicação do periódico Cadernos de Pesquisa com o artigo "A pesquisa educacional brasileira", o único do primeiro volume? . Através dessa publicação, apresenta 

construção de pesquisas científicas...

seu primeiro balanço sobre a pesquisa educacional brasileira, englobando o período de 1940 a 1970 ; e a pesquisa educacional brasileira, à medida que vai se desenvolvendo, continua a ser seu objeto de investigação. Neste artigo enfatizamos sua publicaçáo de 1974 com suas primeiras impressóes sobre a pesquisa educacional desenvolvida em cursos de mestrado, dado o deslocamento da pesquisa em educação de centros de pesquisa para a universidade, através da pós-graduação stricto sensu, desde meados de 1960.

Gouveia (1974) afirma que cursos de pós-graduação em educação, especificamente cursos de mestrado, prescindiam da estrutura adequada para formação através da realização de pesquisas. A preparação adequada de pesquisadores revelava aspectos críticos no início dessa nova fase da pesquisa educacional, sendo esta a "quarta fase". É da autora a afirmação de que os cursos "não se estruturam propriamente em função da preparação de pesquisadores" (GOUVEIA, 1974, p. 500), predominando os "de curta duraçâo que têm se realizado aqui e acolá pelo Brasil” (GOUVEIA, 1974, p. 500). Para ela, a formação de "massa crítica" (GOUVEIA, 1974, p. 500, grifo nosso), necessariamente preparada no país, exigia:

[...] que se concentrassem recursos em torno de pelo menos um programa de pós-graduação bem estruturado, onde, além de assistirem a cursos regulares, os participantes participassem efetivamente da realização de um projeto de pesquisa, desde as fases iniciais da seleção e formulação do problema até a elaboração e análise dos dados.

Segundo sua perspectiva, a formaçáo ideal de pesquisadores educacionais se daria através do desenvolvimento de pesquisas pelos próprios mestrandos, em coletivos de demais mestrandos e professores:

Ao mesmo tempo que se familiarizassem, em situação real, com as dificuldades inerentes às diferentes etapas da execução de um projeto, poderiam, diante dos estímulos decorrentes do intercâmbio de idéias e informaçôes com os participantes do empreendimento comum professores e colegas - sentir-se menos hesitantes e inseguros ao formular e executar a dissertação destinada à obtenção de grau de mestre. (GOUVEIA, 1974, p. 500). 
Esta orientação curricular exigiria, por sua vez, a condição concreta de dedicação integral de professores e alunos, o que à época conflitava com a realização de "cursos esporádicos, promovidos de acordo com 'as disponibilidades orçamentárias' ou ao sabor de orientaçôes variadamente observáveis ao desenvolvimento da pesquisa" (GOUVEIA, 1974, p. 500).

A oficialização da pós-graduação stricto sensu no Brasil resulta em relativa estabilidade do desenvolvimento de pesquisas em educação, como antevê e relata Gouveia $(1971,1974)$. Desde então, em dissertaçôes de mestrado e teses de doutorado, os resultados mais evidentes dos processos iniciais da formação do pesquisador em educação e da dimensão prática da pesquisa na área de educação passaram tanto a ser produzidos quanto analisados, bem como as próprias análises passam a ser publicadas continuadamente a partir dos anos de 1980, especialmente no periódico Cadernos de Pesquisa. Considerando essas análises por distintos pesquisadores da área da educaçáo, identificamos um conjunto de críticas que se fez nessa "quarta fase", usando a periodização de Gouveia (1971), conjunto que tem em comum o apontamento de limites teóricos-metodológicos de pesquisas educacionais, o que passamos a expor. Importante registrar que algumas publicaçôes desse período em Cadernos de Pesquisa não foram consideradas em nossa sumarização, uma vez que, ainda que tratando de pesquisa educacional, não desenvolvem análises da pesquisa educacional brasileira, tendo em vista as questôes metodológicas gerais que dissertaçóes e teses apresentam.

\section{Limites da relação entre teoria e realidade: análises gerais da pesquisa na pesquisa educacional em nível de pós- graduação stricto sensu}

Guiomar Namo de Mello (1983) cunhou uma das primeiras análises gerais do conhecimento produzido através de dissertaçóes, afirmando dois movimentos associados no plano metodológico: pobreza teórica e inconsequência metodológica ${ }^{10}$. Observaçôes semelhantes são feitas por Evaldo Vieira (1988), para quem o modismo e a redundância de análises seriam resultado de um processo de pesquisa com claros limites metodológicos: 
Basta, porém, ler com constância pesquisas universitárias para constatar-se a repetição de temas e de análises, de forma intelectualmente superficial e pobre. É como se, naquele momento, tudo estivesse começando, em fictício vislumbre de inovação, com pouco ou nenhum levantamento de estudos anteriores, não levando em conta a contínua acumulação de conhecimentos. (VIEIRA, 1988, p. 58).

Miriam Warde (1990), à época liderança institucional na área, aponta problemas bastante graves na produção de teses e dissertaçóes em educação: noção evasiva de pesquisa, "estreitamento de temas", "lassidão do método", "produto sincrético" e "formalismo teórico" fazem parte de sua crítica.

Luiz Antonio Cunha (1991) desenvolve uma consideração que direciona e vincula duas dimensôes da pós-graduação em educação: sua institucionalização e seus efeitos. O "improviso" (CUNHA, 1991, p. 63) ou "vícios de origem" qualificam a instalação de cursos de mestrado na área, aproveitando professores e estudantes de distintas formaçóes, sem efetiva tradição de pesquisa antecedente. A conclusão sobre dissertações e teses é em geral, distanciada de análises mais precisas, ácida e contundente: "[...] muitas pesquisas chamadas por esse nome nos programas não podem reivindicar cidadania acadêmica, nem grande parte das dissertaçóes e teses mereceriam sair do esconderijo em que foram, com louvável autocrítica, guardadas por seus próprios autores" (CUNHA, 1991, p. 64). Em outras formulaçôes idênticas no conteúdo e no tom, qualifica teses e dissertaçóes: "Ao lado das teses e das dissertaçóes que contribuíram para inaugurar um novo patamar na carreira de seus autores, existe uma grande massa delas que não serviram para coisa alguma. [...] A verdade é que a maioria das teses e dissertaçóes é muito ruim" (CUNHA, 1991, p. 66). Demais considerações do autor transitam entre explicaçóes de ordem institucional ou subjetiva e reivindicam uma "inflexão" na pós-graduação, necessária a partir desde então.

Bernadete Gatti (1992), uma das autoras que mais tem se dedicado a analisar a pesquisa educacional brasileira, realiza em 1992 uma primeira revisão da literatura publicada sobre a pesquisa educacional brasileira no próprio periódico Cadernos de Pesquisa. Ela reúne nesta revisão literatura 27 artigos do periódico, concentrados, sobretudo, na década de 1980, com contribuiçóes de teorias e métodos diversas e com sensíveis divergências, que têm como substrato a análise da pesquisa educacional brasileira por parte dos autores examinados, 
integrantes de grupos de avalição da pós-graduação em educação, professores de cursos de mestrado e doutorado. Sua conclusão afirma limites teóricos da pesquisa educacional que, a despeito das controvérsias, poderiam figurar como consenso:

O confronto salutar explicitado em todos esses artigos foi o caldo de cultura no qual se tem avançado nas preocupações com a pesquisa em Educaçáo. Conflitos entre posturas epistemológicas, diferenciais de método e de utilizaçấo de técnicas, avanços na explicitação do objeto, problemas de natureza institucional fazem parte do vivido nas lides dos que trabalham com a investigaçáo científica. É preciso reconhecer que não temos nos omitido no enfrentamento desses problemas, mas que, por outro lado, nem tudo que se faz sob a égide de pesquisa educacional pode ser realmente considerado como fundado em princípios de investigação científica, traduzindo com suficiente clareza suas condiçôes de generalidade e, simultaneamente, de especialização, de capacidade de teorização, de crítica e de geração de uma problemática própria, transcendendo pelo método não só o senso comum, mas as racionalizaçóes primárias. (GATTI, 1992, p. 110).

Alda Judith Alves-Mazzotti (2001) propóe, tendo por referência análises de pesquisadores da área e sua experiência como parecerista de projetos de pesquisa e membro de bancas de dissertaçóes e teses, que os produtos da pósgraduação stricto sensu têm se revelado, nos termos da autora, resultado de pesquisas exploratórias sobre temas "irrelevantes", "pulverizados", "pobres" do ponto de vista teórico-metodológico, direcionados à aplicação imediata na prática pedagógica e, ao mesmo tempo, sem consistente debate, impacto prático e ampla divulgação. Para a autora, estas características das teses e dissertaçôes são ao mesmo tempo resultado e resultante de sua "pobreza teórica-metodológica":

[...] o desconhecimento das discussóes teóricometodológicas travadas na área leva muitos pesquisadores iniciantes, principalmente os alunos de mestrado, a permanecerem "colados" em sua própria prática, dela derivando o seu problema de pesquisa e a ela buscando 
retornar com aplicaçóes imediatas dos resultados obtidos. $\mathrm{O}$ fato de que esses estudos costumam ser restritos a uma situação muito específica e de que a teorização se encontra ausente ou é insuficiente para que possa ser aplicada ao estudo de situações semelhantes resulta na pulverização e na irrelevância desses estudos. Por outro lado, a pouca atenção dada ao conhecimento acumulado na área, ao não permitir uma análise mais consistente dos referenciais conceituais disponíveis para a abordagem do tema de interesse, favorece a adesão acrítica a autores "da moda". (ALVES-MAZZOTTI, 2001, p. 41).

Incontornável sublinhar que essas considerações têm forte vinculação ao que aqui tratamos em relação à dinâmica entre objeto real e objeto científico. Essas posiçôes de Alves-Mazzotti (2001) são, em certa medida, a reiteração ampliada de análises suas anteriores (ALVES-MAZZOTTI, 1992), em que reivindica a teorização como movimento inicial de pesquisas, resultantes dos procedimentos de revisão de literatura e de definição de um marco teórico no processo de pesquisa. Esta reivindicação antecedente se fez acompanhar de uma tipologia dos problemas mais comuns identificados em teses e dissertaçóes seja sobre o trabalho teórico, seja sobre a relação entre teorização e dimensão empírica de pesquisas.

Marli André (2001) defende rigor nas pesquisas educacionais das práticas a pesquisa-açáo e a pesquisa do professor reflexivo. Sobre pesquisas educacionais que envolvem a participação do pesquisador na situação pesquisada, "pesquisaação" e "etnografia", lavradas na reivindicação do "professor reflexivo", funda-se numa "supervalorização da prática e um certo desprezo pela teoria" (ANDRÉ, 2001, p. 57), numa polêmica entre saber acadêmico e saber dos práticos, os professores propriamente ditos.

Por fim, Bernadete Gatti (2001) reitera sua exposição de duas décadas em que assinala bastante negativas a pesquisa educacional brasileira, algumas associadas a outras: "dificuldade de criação de categorias teóricas consistentes"; "modismos periódicos"; "apropriaçáo simplificada" de fundamentos de outras áreas; "aplicação ingênua de categorias usadas em outras áreas de estudo"; "frágil tradição de produção científica na área" aliada a "lutas por hegemonias" e manutenção de "posiçôes de poder por grupos"; "imediaticidade" dos resultados de pesquisa; debate apriorístico sobre pesquisas qualitativas e quantitativas que 
implicou tanto em empobrecimento metodológico de pesquisas quantitativas quanto no desenvolvimento de pesquisas qualitativas "casuístas", com referência metodológica restrita à vivência do pesquisador. A autora afirma que a tradição de grupos de pesquisa em educaçâo somente pode ser considerada a partir dos anos de 1980, e mais, que esta tradição realiza-se precipuamente em universidades que, no Brasil, se caracterizam mais pela atividade de formação profissional do que produçáo de conhecimento e menos ainda da discussão sobre a produçáo do conhecimento.

Essas publicaçóes afirmam e reafirmam, ainda que partindo de problemáticas distintas, uma recorrente fragilidade metodológica na pesquisa educacional brasileira até início do século XXI. Nessa sumarização sobre a pesquisa educacional brasileira em sua "quarta fase", identificamos que problemas de ordem teórica e metodológica aparecem como tônica e não exceção: "pobreza teórica" e "inconsequência metodológica", "formalismo teórico"; temas "irrelevantes", "pulverizados" e "pobres" do ponto de vista teórico-metodológico, "supervalorização da prática e um certo desprezo pela teoria", "dificuldade de criação de categorias teóricas consistentes", "apropriaçáo simplificada" de fundamentos de outras áreas, "aplicaçáo ingênua de categorias usadas em outras áreas de estudo", "pesquisas qualitativas casuístas" são os termos enfáticos que qualificam a produção da área de educação, na acepção desses pesquisadores, lideranças nesse período seja na pós-graduação em educação, seja no debate sobre metodologia da pesquisa educacional.

A despeito desses juízos não parecerem ser resultados de trabalho sistemático sobre a produção da pesquisa educacional em nível de pós-graduação stricto sensu e sim expressão de uma posição de liderança que seus autores ocuparam, de nossa perspectiva, essa revisão indica limites que se situam na ordem da relação entre teoria e experiência no desenvolvimento de pesquisas e, consequentemente, na conclusão de dissertaçôes e teses. Nossa suposição é de que tais limites poderiam encontrar solução no desenvolvimento de pesquisas se aprofundadas as teses de Miriam Limoeiro Cardoso de distinção entre objeto real e objeto teórico e de sua consequência metodológica de início do processo de realização de produção do conhecimento científico pela teorização, questão e processo possivelmente ausentes no desenvolvimento de pesquisas na área de educaçáo $0^{11}$. 


\section{Considerações para a atualidade: a relação entre teoria e realidade na pesquisa educacional brasileira no século XXI será um problema metodológico?}

Supomos que limites na relação entre teoria e experiência na pesquisa educacional possam marcar ainda a produção da área, ainda que trabalhemos com a hipótese de um recente salto qualitativo da pesquisa educacional, uma vez que desde 2000 adentramos uma nova fase de pesquisa educacional, correspondente a contextos institucionais diferenciados na dinâmica da pósgraduação brasileira. Em que pese essa perspectiva, passados quarenta anos de institucionalização da pós-graduação, Acácia Kuenzer e Maria Célia Marcondes de Moraes (2005) apontam a possibilidade da persistência de limites na relação entre teoria e experiências no desenvolvimento de pesquisas.

Na perspectiva de Kuenzer e Moraes (2005), se até meados de 1990 a regulação da pós-graduação stricto sensu brasileira se orientava mais pela finalidade de formação de professores para o ensino superior do que outras, desde então a produção de conhecimento e a pesquisa nucleariam a avaliação e o desenvolvimento de cursos e programas de pós-graduaçáo stricto sensu ${ }^{12}$. Tal mudança mereceu considerar o conteúdo de pesquisas de pós-graduação stricto sensu em educação; as atoras, em suas formulaçôes, colocam: "[...] que tipo de conhecimento é produzido? Qual a compreensão de pesquisa que prevalece?” (KUENZER; MORAES, 2005, , p. 1352).

A questão epistemológica geral proposta pelas autoras gira em torno do que Moraes (2001) denominou "recuo da teoria", tendência epistemológica contemporânea filiada ao neopragmatismo que, em síntese bastante ampla, reivindica tanto a negaçáo da racionalidade em geral e da cientificidade, em particular, como fundamento da possibilidade de produçáo de conhecimento quanto a defesa de um renovado empirismo que centraliza na experiência vivida o fundamento e a finalidade de pesquisas nas ciências sociais e humanas em geral e também na área de educação. Kuenzer e Moraes (2005) veem sob a ótica desse recuo os resultados de pesquisas em pós-graduação stricto sensu em educação e apontam as perspectivas dominantes metodológicas segundo uma tipologia daí derivadas. Assim, descrevem-nas:

a) como simples levantamento de dados fenomênicos; b) por restringir seu horizonte ao controle desses dados com 
vistas a descrever seu provável comportamento futuro; c) por pensá-las como mera estratégia de intervenção; d) ou ainda, em suas versóes "pós" ou "neo", por reduzilas a "narrativas fragmentadas, descriçóes vulgares das múltiplas faces do cotidiano escolar (Moraes e Müller, 2003, p. 2). (KUENZER, MORAES, 2005, p. 1352).

Ainda que haja diferenças teóricas entre as publicaçóes nos Cadernos de Pesquisa até o ano de 2001 e a publicação de Kuenzer e Moraes (2005), todo esse conjunto de publicaçóes afirma limites nas pesquisas desenvolvidas através da pós-graduação stricto sensu, mais especificamente, limites na relação entre teoria e experiência. Além de consideraçôes desses limites metodológicos de pesquisas educacionais, identificamos possíveis explicaçóes e soluçóes curriculares e institucionais para esses próprios limites. A relação entre problemas de ordem teórica e o currículo da formação desenvolvida na pós-graduação stricto sensu em educação já era tratada por Gouveia (1974), para quem ao invés de intensificação de estudos profissionais, a realização de pesquisas em grupos e seu debate entre mestrandos e professores seria o método ideal da formação de pesquisadores em educação. Kuenzer e Moraes (2005) sugerem que a realização de pesquisas seja acompanhada de debate epistemológico que, ausentado da própria formação de mestres e doutores, responderia, em grade parte, pela dificuldade de desenvolvimento de pesquisas com aporte teórico, tal qual reivindicam.

Também registramos que relaçôes entre os limites metodológicos e a dimensão institucional, com efeitos curriculares, são objeto de análises, essas mais conjunturais. Em meados da década de 1970, Gouveia (1974) apontava que a instabilidade da carreira de docentes ou de pesquisas constrangiam o desenvolvimento de pesquisas. Em meados de 2000, para Kuenzer e Moraes (2005), o problema se concentra no curto período formação de mestres, formação inicial da pós-graduação stricto sensu ${ }^{13}$. Para essas autoras, a redução do tempo de formação de mestres, sobretudo, mas também de doutores, limita ou exclui a possibilidade de debate epistemológico para o desenvolvimento de pesquisas. A medida de reduçáo do tempo de formação no mestrado de trinta para vinte e quatro meses, por exemplo, desconsiderou o fato de que "neste nível, a inexperiência em pesquisa, articulada à não rara fragilidade da formação teórica anterior, demandaria um tempo maior para o amadurecimento acadêmico de grande parte dos alunos" (KUENZER; MORAES, 2005, p. 1349). As consequências dessa redução em termos curriculares são a impossibilidade 

construção de pesquisas científicas...

[...] do contato dos alunos com temas diversos e literatura original, hoje praticamente impossível nos seminários de pesquisa formatadores de dissertaçôes de curto prazo. Este é, talvez, o impacto mais notável do processo que fragilizou a formação de pesquisadores neste nível de ensino. (KUENZER; MORAES, 2005, p. 1349).

A contundência das críticas de Kuenzer e Moraes (2005) sobre a pesquisa educacional, e nossa interpretaçáo de que a atualidade dessas proposiçóes se soma a um conjunto de análises que sempre assinalou limites metodológicos na pesquisa educacional nos motivam a tratar de (im)possibilidades de superação.

De nossa parte, consideramos que a problematização da pesquisa educacional é necessária: a crítica e autocrítica teórica, metodológica, epistemológica e institucional são imprescindíveis e típicos do desenvolvimento científico. Pelo que expusemos, a ausência de um processo de teorizaçáo, resultado de uma posição mais ou menos consciente, conduz certamente à redução ou à negação da construção da objetividade do conhecimento produzido na área de educação, comprometendo a eficácia da produção teórica, com implicaçóes políticas nada desprezíveis. Nossa hipótese considera que a tendência de "pobreza teórica" ou "recuo da teoria" pode ser superada, se consideramos além de sua explicação metodológica o seu enraizamento epistemológico. Em outras palavras, supomos que não encontraremos a superação dos limites entre teoria e realidade apenas através da reivindicação de maior rigor e coerência na coleta e/ou tratamento de dados em pesquisas qualitativas e pesquisas quantitativas ou da junção desses dois tipos de pesquisa ${ }^{14}$, mas compreendendo-os num plano teórico, como sendo parte de questóes cruciais - o estatuto do conhecimento científico e de realidade. Nessa direçấo, as contribuiçóes metodológicas de Miriam Limoeiro Cardoso podem revelarse fecundas no desenvolvimento de pesquisas educacionais e apresentamo-las como proposiçáo sintética de alguns dilemas passados e possivelmente ainda presentes na pesquisa educacional brasileira.

A despeito de considerarmos que na realização de pesquisa seja mais do que possível, e sim necessária uma vigilância teórica e metodológica ativa do pesquisador, ou seja, de reivindicarmos estreito controle de ordem da 
racionalidade investigativa no desenvolvimento de pesquisas, entendemos também que exigências racionais supóem determinadas condiçóes para o exercício de pesquisas que podem, ou não, estar presentes ou ainda, podem ser valorizadas na área ou entre grupos específicos da área.

$\mathrm{Na}$ exploração do debate sobre pesquisa educacional brasileira, desenvolvida ao longo da pós-graduação stricto sensu, nosso pressuposto, de fundo histórico, é a de que a sua institucionalidade tem balizado o exercício desta vigilância. Assim, no limite, em nossa análise ao mesmo tempo em que reconhecemos uma possível fecundidade que o exame e o debate das considerações de Miriam Limoeiro Cardoso sobre construção teórica da realidade social podem resultar na produção de conhecimento da área de educação, colocamos esta possibilidade como negação, como impossível para a formação do pesquisador em educação, se consideramos constrangimentos institucionais, de diversas ordens, postos pela dinâmica da pesquisa em pósgraduação stricto sensu brasileira em geral.

\section{Notas}

${ }^{1}$ Disponível na rede mundial de computadores. Em fins de 2013, identificamos quatro diferentes endereços da publicação. Utilizamos: http://www.slideshare.net/josericardorocha/28978148-miriamlimoeiro cardosoomitodometodo. Acesso em: ago. 2009.

2 Limoeiro Cardoso, em 1972, refere-se a esta notação metodológica de Marx como Prefácio e nas publicaçóes posteriores, de 1977 e 1990, como Introdução.

${ }^{3}$ Em nossa coleção da produção da autora, há ainda três artigos de 1994, 1995 e 1996, divulgados através do sítio eletrônico do Instituto de Estudos Avançados da Universidade de São Paulo (IEA-USP); cinco capítulos em livros organizados, alguns por pesquisadores da área de educação: de 1990 a 2006. As últimas contribuiçôes que temos da autora não são impressas, mas fontes sonoras de suas intervençóes em dois distintos eventos acadêmicos da área de educação, em fase de transcriçãa. Nosso levantamento ainda prossegue através da exploração de outro conjunto de escritos que se relacionam mais diretamente a sua militância sindical no movimento docente, através de sua participação no 

construção de pesquisas científicas...

debate sobre educação na Assembleia Constituinte, que promove reforma constitucional no país, no final dos anos de 1980.

${ }^{4}$ Iniciando inclusive por analisar teoricamente as percepçóes subjetivas, o que sugere um necessário movimento de autocrítica. Não foi outro senão esse o movimento original das ciências.

${ }^{5}$ Em amplo sentido, este outro pode ser modulação do conhecimento teórico inicial ou também sua confirmação e negação.

${ }^{6}$ Dados os limites deste artigo, não consideramos outros movimentos necessários na produção do conhecimento científico: a relaçáo entre objeto teórico e objeto real e também a relação entre conhecimento científico e conhecimento objetivo, questóes tratadas por Miriam Limoeiro Cardoso. Assinalamos apenas suas contribuiçóes a respeito da experimentação como confrontação entre o objeto teórico e objeto real no processo da pesquisa (CARDOSO, 1978), e da objetivação como expressão da dimensão coletiva do trabalho científico, uma vez que o debate e o confronto entre objetos teóricos são os movimentos que podem aquilatar maior ou menor aproximação entre objeto teóricos e objeto real (CARDOSO, 1979).

${ }^{7}$ Há ainda artigos após 2000 que tratam da dimensão metodológica de pesquisas educacionais, predominando os que tratam de relaçóes entre pesquisa e ação pedagógica e sumarização de pesquisas de um campo disciplinar ou perspectiva teórica específica (pesquisa sobre currículo, pesquisas pós-críticas).

${ }^{8}$ Menga Lüdke (2002), autora do verbete Aparecida Joly Gouveia, em Dicionário de Educadores no Brasil, apresenta sua trajetória profissional dinâmica que inicia sua formação como normalista em 1940, em 1950 graduou-se como socióloga pela Universidade de São Paulo (USP), Doutora em Sociologia pela Universidade de Chicago em 1962, e professora de graduação e pós-graduação no Departamento de Sociologia da Faculdade de Filosofia, Ciências e Letras da USP, além da participação em várias instituiçóes de pesquisa social e pesquisa educacional como INEP, CBPE, ANPOCS, FAPESP, CNPq, entre outras.

${ }^{9}$ Este artigo, ainda em 1971, mereceu reedição na Revista Brasileira de Estudos Pedagógicos, o primeiro e mais longevo periódico sobre educação no país, editado desde 1944, na Revista del Centro de Estúdios Educativos do México. 
${ }^{10}$ Sua análise tem acordo de Gatti (1983).

${ }^{11}$ A análise de cursos de mestrado em educação no Brasil entre 1960 e 1980 nos fornece fortes indícios de que a teorização não se colocava como dimensão curricular na formação de mestres em educação, uma vez que demonstrou que a denominação das áreas de concentração dos cursos de mestrados incidiam sobre aspectos da profissão pedagógica (e não sobre campos teóricos ou mesmo disciplinas científicas) e também por constar em documentação oficial desses cursos a afirmação da ausência de tradição de pesquisas como característica da área.

${ }^{12}$ Para as autoras, esse redirecionamento, que se enraíza na planificação de Estado e se dinamiza através de uma nova sistemática de avaliação da pós-graduação stricto sensu, que valorizaria a cientificidade, é positivo. Essa aposta, em nosso entender, é uma questáo em aberto e merece uma verificação de longo prazo.

${ }^{13}$ Do conjunto dos artigos de Cadernos de Pesquisa que tratam da pesquisa educacional até o ano de 2001, incluindo alguns que aqui não expusemos por tratarem, por exemplo, de política de pós-graduação ou de métodos e técnicas de pesquisa, a instabilidade no financiamento de cursos ou de bolsas de pesquisa para professores e estudantes, aparece frequentemente como problema.

${ }^{14}$ Não estamos de acordo com essa distinção, bastante difundida na área de educação, uma vez que quantidade e qualidade são dimensôes inseparáveis da realidade.

\section{REFERÊNCIAS}

ALVES-MAZZOTTI, Alda Judith. Revisões bibliográficas em teses de mestrado e doutorado: meus tipos inesquecíveis. Cadernos de Pesquisa, São Paulo, n. 81, p. 53-60, 1992.

ALVES-MAZZOTTI, Alda Judith. Relevância e aplicabilidade da pesquisa em educação. Cadernos de Pesquisa, São Paulo, n. 113, p. 65-81, 2001.

ANDRÉ, Marli. Pesquisa e educação: buscando rigor e qualidade. Cadernos de Pesquisa, São Paulo, n.113, p. 51-64, 2001. 

construção de pesquisas científicas...

CARDOSO, Miriam Limoeiro. O mito do método. Boletim Carioca de Geografia, Rio de Janeiro, ano 25, p. 61-100, 1976.

CARDOSO, Miriam Limoeiro. La ideología dominante. Mexico: Siglo Vinteuno, 1975.

CARDOSO, Miriam Limoeiro. La construcción de conocimientos: cuestiones de teoria y método. México: Era, 1977.

CARDOSO, Miriam Limoeiro. Ideologia do desenvolvimento: Brasil: JK JQ. Rio de Janeiro: Paz e Terra, 1978.

CARDOSO, Miriam Limoeiro. Para o conhecimento dos objetos históricos: questôes metodológicas. Rio de Janeiro: Cadernos da EIAP, 1979.

CARDOSO, Miriam Limoeiro. Para uma leitura do método em Karl Marx: anotaçôes sobre a "Introdução" de 1857. Cadernos do ICHF, Niterói, n. 30, p. 1-56, 1990.

CUNHA, Luiz Antônio Pós-graduação em educação: no ponto de inflexão. Cadernos de Pesquisa, São Paulo, n. 77, p. 63-80, 1991

GATTI, Bernadete Angelina. Pós-graduação e pesquisa em Educação no Brasil, 1978-1981. Cadernos de Pesquisa, São Paulo, n. 44, p. 3-17, 1983.

GATTI, Bernadete Angelina. Pesquisa em Educação: um tema em debate. Cadernos de Pesquisa, São Paulo, n. 80, p. 106-112, 1992.

GATTI, Bernadete Angelina. Implicaçóes e perspectivas da pesquisa educacional no Brasil contemporâneo. Cadernos de Pesquisa, São Paulo, n. 113, p. 65-81, 2001.

GOUVEIA, Aparecida Joly. A pesquisa educacional no Brasil. Cadernos de Pesquisa, São Paulo, n. 1, jul., p. 1-48, 1971.

GOUVEIA, Aparecida Joly. Algumas reflexôes sobre a pesquisa educacional brasileira. Revista Brasileira de Estudos Pedagógicos, Brasília, DF, v. 60, n. 136, p. 496-500, 1974.

GOUVEIA, Aparecida Joly. A pesquisa sobre educação no Brasil: de 1970 para cá. Cadernos de Pesquisa, São Paulo, n. 19, p. 75-79, dez. 1976. 
KUENZER, Acácia Zeneida; MORAES, Maria Célia Marcondes de. Temas e tramas na pós-graduação em educação. Educação \& Sociedade, Campinas, SP, v. 26, n. 93, p. 1341-1362, 2005. Disponível em: <http://www.scielo.br/ pdf/es/v26n93/27284.pdf>. Acesso em: 27 jan. 2010.

LUDKE, Menga. Aparecida Joly Gouveia. In: FÁVERO, Maria de Lourdes de Albuquerque; BRITTO, Jader de Medeiros (Org.). Dicionário de

Educadores no Brasil: da Colônia aos dias atuais. 2. ed. Rio de Janeiro: Editora da UFRJ, 2002.

MARX, Karl. Contribuição para a crítica da economia politica. Lisboa: Editorial Estampa, 1974, pp. 228 - 237.

MELLO, Guiomar Namo de. A pesquisa educacional no Brasil. Cadernos de Pesquisa, São Paulo, n.46, p. 67-72, 1983.

MORAES, Maria Célia Marcondes de. Recuo da teoria: dilemas da pesquisa em educação. Revista Portuguesa de Educação, Lisboa, v. 14, n. 1, p. 7-25, 2001.

VIEIRA, Evaldo. Pesquisa em educação: quando se é específico? Cadernos de Pesquisa, São Paulo, n. 67, p. 56-58, 1988.

WARDE, Miriam Jorge. O papel da pesquisa na pós-graduação em educação. Cadernos de Pesquisa, São Paulo, n. 73, p. 67-75, 1990. 

construção de pesquisas científicas...

Bienes primacía en Real primacy in the la construcción del construction of scientific conocimiento científico y knowledge and the la primacía de la teoría primacy of theory in the en la construcción de la construction of scientific investigación científica: research: methodological aportes metodológicos de contributions from Miriam Miriam Limoeiro Cardoso Limoeiro Cardoso

\section{Resumen}

Reivindicamos en relación a la posibilidad de desarrollar investigaciones educacionales que tengan como referencia la contribución metodológica de Miriam Limoeiro Cardoso, esta posición considera dos movimientos de investigación. Primero, exponemos la problemática de nuestras investigaciones - una síntesis parcial de los análisis sobre investigación educacional en posgrado stricto sensu entre los ańos 1970 y 2000 que señalan una recurrente fragilidad epistemológica. A continuación nos referimos a la contribución de Miriam Limoeiro Cardoso, cientista social brasileña que nos ha legado, desde la década de 1970 hasta hoy, una importante tesis sobre el pensamiento social brasileño y contribuciones de síntesis en el campo del marxismo, desde el punto de vista epistemológico. La posible fecundidad del debate sobre sus contribuciones no resulta de un asunto meramente teórico sino institucional y relativo a la dinámica de la política científica más general y de su traducción en el área educacional.

\begin{abstract}
In this article it is claimed the possibility of developing educational research bearing in mind Miriam Limon Cardoso's reference to the methodological contribution, a position that involves two research movements. At first, it is exhibited the thesis of the distinction between reality and scientific object and of the theorization as the initial process of the research object construction, which synthesize the examination which the author undertake from Karl Marx's methodological notes in his process of elaboration of a general capitalism theory. The possibility of fecundity of her contributions result from the verification of problems between theory and practice that is identified by summarizing the analysis of the Brazilian educational research up to the beginning of this century, which is still current.
\end{abstract}

Keywords: Scientific knowledge. Miriam Limoeiro Cardoso. Educational Research. 
Palabras claves: Investigación educacional;

Posgrado stricto sensu; Conocimiento científico; Miriam Limoeiro Cardoso.

\section{Rosa Maria Corrêa das Neves}

E-mail: rosamcneves@gmail.com

\section{Siomara Moreira Vieira Borba}

E-mail: siomaraborba@gmail.com

Enviado em: 24/9/2014

Aprovado em: 8/12/2014 